\title{
Revisión de estudios sobre el VIH/sida y los modelos de sexualidad nicaragüenses
}

\author{
Itahisa Pérez Pérez ${ }^{1}$
}

\section{RESUMEN}

Este artículo es producto de la revisión de estudios sobre VIH/sida desarrollados en Nicaragua, desde el año 2000 hasta la actualidad, y forma parte del proyecto denominado "Conocimientos y prácticas de riesgo en VIH/sida. Una estrategia de Cooperación en Educación para el Desarrollo en Nicaragua", desarrollado por la Universidad Pablo de Olavide (UPO) y la Facultad Regional Multidisciplinar de Chontales (FAREM-Chontales) de la Universidad Nacional Autónoma de Nicaragua, Managua. Con objeto de elaborar un marco teórico sobre estudios científicos en VIH/ sida desarrollados en Nicaragua, y la cultura sexual que existe en la juventud nicaragüense, se ha realizado esta revisión bibliográfica de los últimos quince años. Se trata de 9 estudios realizados en Nicaragua para conocer la situación del VIH/sida en dicho país y configurar el perfil de la infección nicaragüense. Además, exponemos los modelos de sexualidad que se dan en Nicaragua ya que nos ayuda a comprender la cultura y educación sexual que existe entre la población. Concluimos que la epidemia sigue aumentando, aunque de manera controlado, en Nicaragua. Tiene un perfil de población joven, entre 15 y 39 años, mayoritariamente de hombres, y con orientación heterosexual, si bien algunos estudios señalan la posibilidad de que dentro de esa población existan Hombres que tienen sexo con otros hombres, población trans y mujeres y hombres trabajadores sexuales que, por estigmas o discriminación, no se hacen visibles. Con estos datos, se reafirma la necesidad de educar y formar a la población, sobre todo a la población joven, que es la población de riesgo y el futuro de la sociedad, para convertir los factores de riesgo en factores de protección y porque solo a través de la educación, se consigue una prevención eficiente y un verdadero cambio social.

Palabras clave: VIH/sida, educación, prevención, epidemia, cultura, sexualidad.

Recibido: 11 de abril de 2016

Aceptado: 14 de octubre de 2016

1 Doctora en Desarrollo y Ciudadanía: Derechos Humanos, Igualdad, Educación e Intervención Social. Docente e investigadora de la Universidad Pablo de Olavide. Campos de interés: pedagogía social/educación social, educación y promoción de la salud, VIH/sida, educación para el desarrollo y animación sociocultural. Correo electrónico: itahisaperez@gmail.com. 


\title{
Review of studies about HIV/AIDS and the model of Nicaraguan sexuality
}

\begin{abstract}
This article derives from the review of studies on HIV/AIDS, developed in Nicaragua from the year 2000 to the date, and is part of a project called "Conocimientos y Prácticas de Riesgo en VIH/sida. Una estrategia de Cooperación en Educación para el Desarrollo en Nicaragua" (Knowledge and Practices of Risk of HIV/AIDS. A Strategy of Cooperation in Education for the Development in Nicaragua), developed by Universidad Pablo de Olavide (UPO) and Facultad Regional Multidisciplinar de Chontales (FAREM-Chontales), of Universidad Nacional Autónoma de Nicaragua, Managua. In order to create a theoretical framework of scientific studies developed in Nicaragua on HIV/AIDS and the sexual culture of Nicaraguans, a bibliographical revision of the last fifteen years was made. Nine studies were revised in total. We conclude that the epidemics continue to increase in Nicaragua, even though it occurs in a controlled way, among the young population between 15 and 39 years, mainly in men with heterosexual orientation. Some studies reveal the possibility of men that have intercourse with other men within that population. The population of transsexuals and sexual workers are not visible, due to discrimination. Taking these data into account, the need of educating the population and especially the young sector is highly important, as they are the in a high risk. Only education can achieve an efficient prevention and a real social change.
\end{abstract}

Key words: HIV/AIDS, education, prevention, epidemics, culture, sexuality. 


\section{INTRODUCCIÓN}

En la tierra de lagos y volcanes no existe una amplia documentación y datos estadísticos sobre conocimientos, prácticas de riesgo y cultura sexual, debido al tabú que ha representado durante décadas estos temas. Sin embargo, algunos autores y organismos en los últimos años han realizado exploraciones sobre zonas concretas del país.

Por un lado, Montenegro (2000) realiza un estudio centrado en la cultura sexual en los habitantes del casco urbano de Managua, con edades comprendidas entre los 15 y 40 años, resaltando las diferencias en cuanto al género. La elección de la zona urbana es debido al gran número de población a la que podían acceder, en contraposición con las zonas rurales o extrarradios.

La segunda investigación revisada corresponde a la del Banco Mundial a través de su Programa Global de VIH/sida en América Latina y el Caribe. Este estudio se desarrolló para apoyar el diálogo actual en la política para fortalecer la respuesta nacional del VIH/sida en relación a (Banco Mundial, 2006):

- Fortalecimiento del liderazgo político y compromiso para preparar un plan de acción regional y políticas comunes.

- Fortalecimiento y armonización del marco legal e institucional para tratar la epidemia de VIH/sida

- Identificación y difusión de "mejores prácticas" para la prevención a través de esfuerzos integrados por el sector salud, otras agencias gubernamentales $\mathrm{y}$ la sociedad civil y promover monitoreo $\mathrm{y}$ evaluaciones de impacto.

- Promover el proceso de adquisición regional relacionado con medicinas, equipos y otros insumos relacionados al VIH.

La información que recoge este informe corresponde con entrevistas realizadas a personas claves en Centroamérica así como de la revisión documental de organizaciones nacionales, las ONG y las organizaciones de desarrollo bilateral e internacional.
Este estudio se presenta en diversos informes. El primero de ellos presenta la situación del VIH en Centroamérica y los otros seis describen la situación de cada uno de los países de dicha región. Nosotros recogeremos los datos correspondientes a Nicaragua aunque relacionándolos con los países fronterizos.

En tercer lugar, expondremos las conclusiones de la investigación llevada a cabo por nuestro grupo de investigación, que fue unos de los pioneros en las relaciones entre la UPO y la Universidad Nacional Autónoma de Nicaragua-Managua (UNAN-Managua) y más concretamente con el Centro Universitario Regional de Chontales (Cur-Chontales).

Este proyecto surge como demanda específica de la UNAN-Managua para ahondar en los conocimientos $\mathrm{y}$ actitudes tanto de estudiantes como profesorado en su Centro Regional de Chontales con sede en Juigalpa. Bajo el título "Sida: conocimientos, actitudes y prácticas de riesgo en estudiantes y profesores en el CUR-Chontales de la Universidad Nacional Autónoma de Nicaragua-Managua. Propuestas para un modelo de Educación Preventiva" esta investigación desarrollada por la UPO se hizo participativamente con el CURChontales en todas sus fases: diseño, desarrollo y análisis.

Los resultados de la misma permitieron explorar las necesidades en materia de formación y promoción de la salud que tienen en el centro. Se convirtió en el primer paso de un largo proceso de desarrollo de una nueva cultura preventiva entre la población estudiantil y académica de Chontales.

Dos años más tarde, la Asociación Xochiquetzal desarrolla un estudio sobre "Seroprevalencia VIH/ Sida, prácticas sexuales y uso del condón en jóvenes de 18 a 30 años". En él pretenden identificar los factores más relevantes que vinculan el riesgo ante el VIH con la capacidad de protección de los jóvenes en diferentes municipios del Pacífico de Nicaragua, estableciendo 
asociaciones muy interesantes que obligan a reflexionar sobre la diversidad de factores que intervienen en su capacidad de protección y que se deben abordar de acuerdo a su propia realidad.

Los municipios elegidos pertenecen a los territorios de intervención de la Fundación Xochiquetzal, que fuesen representativos de diferentes tejidos sociales y con una situación de VIH en los mismos. Estos municipios son: Managua, Ciudad Sandino, Tipitapa, Distrito III, Distrito IV, Pochomil (Departamento de Managua); Chinandega, Corinto, Somotillo y Villa Nueva (Departamento de Chinandega); Masaya, Niquinohomo y Nindiri (Departamento de Masaya); y, por último, Rivas, San Juan del Sur, Potosí y San Jorge (Departamento de Rivas).

En 2012 la Organización Internacional del Trabajo OIT- lleva a cabo el proyecto de prevención y mitigación del impacto del VIH y el Sida en el mundo del trabajo denominado: "Conocimientos, actitudes y prácticas sobre el VIH y el Sida en población trabajadora de la Maquila en Nicaragua".

Este proyecto es continuación del desarrollado en el periodo 2009-2011, también por la OIT, "Prevención y mitigación del impacto del VIH y el Sida a partir del mundo del trabajo en Nicaragua", centrado en la maquila textil y la confección. Tras los resultados obtenidos se diseña este estudio con el apoyo del Centro de Investigación en Salud, Trabajo y Ambiente de la Universidad Nacional Autónoma de Nicaragua-León (UNAN-León). Se identificaron las vulnerabilidades existentes en la población trabajadora de las empresas del sector maquila, sobre sus conocimientos, actitudes y prácticas en relación al VIH y el sida.

A continuación revisamos el estudio sobre VIH/sida desarrollado, y primero con resultados conocidos en la ciudad de Juigalpa, por la FAREM-Chontales, la Universidad Pablo de Olavide, y dentro de la Convocatoria de Proyectos de Solidaridad y
Cooperación al Desarrollo del Excelentísimo Ayuntamiento de Dos Hermanas (Sevilla, España) en 2012 denominado "Desarrollo comunitario y mejora y calidad de vida en Juigalpa (Nicaragua) III Fase UNAN-Managua FAREM-Chontales, Nicaragua en Drogodependencia, Conductas Sexuales de Riesgo, Prevención de VIH/sida y Salud Laboral".

Este proyecto se centró en fortalecer las acciones institucionales en la promoción de salud y prevención de conductas de riesgo en la población vulnerable de la ciudad de Juigalpa. Entre las acciones implementadas se encontraron:

- Reactivación de las comisiones Observatorio Centroamericano sobre Violencia -OCAVI- y Comisión de Padres y Madres de Familia COPAMA-.

- Consolidación de los grupos voluntarios.

- Actividades (foros, talleres educativos, programas radiales, ligas del saber y murales informativos intercolegiales).

El objetivo fundamental del estudio era propiciar mayor sensibilización, prevención e incremento de la promoción en los estilos de vida saludables en la población de Juigalpa, a través de acciones de seguimiento a la investigación, educación y promoción de buenas prácticas en salud, al intercambiar experiencias entre instituciones involucradas y la población vulnerable.

La población a la cual destinaron este estudio fue a 18.498 jóvenes en riesgo con edades comprendidas entre los 10 y 19 años de edad, 5.462 estudiantes, siendo beneficiarios indirectos entorno a 59.002 sobre el conjunto de la población del municipio.

A continuación, recogemos resultados del último proyecto de investigación de la Universidad Pablo de Olavide llevado a cabo en población universitaria de la FAREM-Chontales y presentado en 2013 en Juigalpa. 
El mismo se titula "Conocimientos y prácticas de riesgo en VIH/sida. Una estrategia de Cooperación en Educación para el Desarrollo en Nicaragua".

Este proyecto se centra en el sida y el VIH desde una perspectiva socioeducativa como base para la cooperación y la educación para el desarrollo (EpD). Desde un enfoque multimétodo, el estudio ofrece una panorámica amplia sobre la situación de la juventud chontaleña con respecto al VIH/sida (PérezPérez, 2014). Su objetivo principal era conocer los conocimientos y prácticas de riesgo de los estudiantes de la FAREM-Chontales acerca del VIH/sida, así como identificar las diferencias que pueden existir en cuanto al género.

Por último, tanto el estudio de PASCA (2013) Situación de ITS, VIH y Sida en Nicaragua, Monitoreo y evaluación de avances para contener la epidemia", que parte de los indicadores del Plan de Monitoreo y Evaluación Nacional de VIH correspondiente al Plan Estratégico Nacional 2012-2015, como la "Situación epidemiológica del VIH y TAR en Nicaragua" (UNAIDS, 2014) dan a conocer la situación de la epidemia del VIH y la respuesta de Nicaragua.

Ambos estudios confirman que la epidemia en Nicaragua sigue en aumento, aunque relativamente controlado, y se da mayoritariamente en la población joven (de 15 a 39 años), y con orientación heterosexual en el $92 \%$ de los casos, si bien se señala en el estudio que "es probable que exista población clave aún no visible por el estigma y discriminación existente" (UNAIDS, 2014: 8), entendiéndose por población clave a HSH, trans, mujeres trabajadoras sexuales (MTS) y hombres trabajadores sexuales (HTS).

\section{RESULTADOS DE LA REVISION DOCUMENTAL}

A continuación, exponemos cada uno de los estudios mencionados anteriormente, centrándonos en los resultados y conclusiones de cada uno de ellos ya que apoyan y potencian nuestra investigación de 2013 (Pérez-Pérez, 2013).

\section{Cultura sexual en población del casco urbano de Managua, 2000}

Nos encontramos ante un panorama de sexualidad como escisión sexo-afectiva para ambos géneros. Entendiendo el sexo como placer y una forma de comunicación de los sentimientos, según Montenegro (2000) los datos sugieren que estamos ante un ejercicio de la sexualidad heterosexual poco gratificante, sobre todo para las mujeres.

Otro aspecto importante es que hablar de temas sexuales con su pareja sólo lo hacen el $0,1 \%$ de los informantes, mientras que con los amigos lo hacen un $76 \%$ (tanto de hombres como de mujeres). Estos datos han aparecido también en nuestro estudio, aunque en menor medida porque las nuevas generaciones se han ido abriendo en cuento a cultura sexual y rechazo de ciertos tabúes. Esto refleja una ausencia de intimidad emocional en las parejas (Montenegro, 2000).

Otro aspecto importante y que coincide con nuestra investigación es que la pareja es algo finito e inestable y que en la realidad se aleja del ideal de "una pareja para toda la vida". Por otra parte, la infidelidad y la falta de responsabilidad fueron las causas más alegadas por las mujeres, mientras que para los hombres fueron la infidelidad y la falta de atención de parte de la pareja. Un $60 \%$ de las separaciones terminaron mal, alegando las mujeres que la ruptura había sido por abandono y conflicto.

En estas rupturas suelen ser los hombres los que abandonan a las mujeres. Según el triángulo de Sternberg, los datos indican que las relaciones de la pareja heterosexual nicaragüense promedio carecen de equilibrio, en tanto se caracterizan por el hecho de que las necesidades de uno de los integrantes sobrepasan 
en exceso a las de otro, o en el que las necesidades de ambos integrantes difieren de modo excesivo (Montenegro, 2000).

Un aspecto importante del estudio que realizó Montenegro hace una década y que pudimos confirmar en la observación realizada en Juigalpa y conversaciones con los jóvenes universitarios y personajes claves, son los guiones sexuales. Durante años los padres y madres han transmitido aquellos valores culturales que consideraban imprescindibles según el género de sus hijos. Para las niñas es conocida la frase "las mujeres no deben andar en la calle" y, en el caso de los niños "los valores son valores y pueden hacer lo que quieran” (op. Cit, p. 195).

En la realización de los cuestionarios salieron a relucir algunas contradicciones sobre la edad temprana de relaciones sexuales, y quisimos indagar con las entrevistas y grupos focales, esa posible y "supuesta" mentalidad machista. Posteriormente se ha confirmado, aunque se ha avanzado, aún queda mucho arraigado.

En Nicaragua, como ocurre en otros contextos de gran arraigo del modelo genérico de la sexualidad, existe una moral sexual diferente para cada sexo. Los hombres tienen legitimado el deseo y la libre expresión de su sexualidad, mientras que las mujeres deben reprimir el suyo. Según Branden (1985), se trata del "dilema de la feminidad", donde la joven para ser mujer debe acceder a la sexualidad, pero para ser una mujer respetable debe reprimir su deseo.

En cuanto a la edad y los motivos para tener su primera relación sexual (Montenegro, 2000), el 76,4\% afirmó que decidieron tener su primera relación sexual por "amor", mientras que en el caso de los hombres sólo fue un 19,8\%, con una edad media de inicio de 16-19 años, retrasándose de 3 a 4 años en comparación con los varones.
Estos resultados no coinciden con nuestra investigación ya que, aunque el cuestionario reflejaba la edad de inicio entorno a la adolescencia (sobre los 16 años), con las entrevistas, los grupos focales y los datos del SILAIS se confirmó que existen relaciones sexuales muy tempranas, en torno a los 12-14 años unido a los embarazos no deseados en adolescentes.

En ocasiones, estos embarazos no deseados son consecuencia de la desinformación o falta de conciencia sobre los métodos de protección, pero también se debe a situaciones de prostitución, abusos o, incluso, como una forma de emanciparse y lograr la tan ansiada "realización del yo" al llegar al estatus de "madre": huída del maltrato familiar, liberación del control y subordinación del hogar, símbolo de madurez, etc., aunque la madurez suele ser una falsa expectativa (Montenegro, 2000).

La socialización de género ha provocado un sentimiento narcisista en los hombres al tener expectativas de ser amados y atendidos, alejándose de las expectativas del amor mutuo. Los hombres buscan: una enfermera, madre, esposa, querida o musa, es decir, prácticamente cualquier cosa menos una persona trascendente por derecho propio (op. Cit, p. 201).

Otro de los aspectos que analizamos en nuestra investigación y que Montenegro también lo recogió fueron las relaciones extramatrimoniales. Para los hombres se consideran "la búsqueda de emoción y variedad sexuales, que no encontraban en sus parejas estables" (op. Cit, 201).

El comportamiento narcisista que muchos hombres muestran en Nicaragua provoca, entre otros aspectos ya mencionados, violencia marital. El hombre amante nicaragüense desemboca en celos $\mathrm{y}$, a menudo, en violencia contra la mujer, aunque también, según los propios hombres, en infidelidad y promiscuidad sexual masculina. La infidelidad en el estudio de Montenegro (2000) fue la principal causa de ruptura 
de pareja y la cuarta la violencia doméstica $\left(2^{\circ}\right.$ la falta de responsabilidad y $3^{\circ}$ falta de atención a la pareja y ausencia de afecto).

Otra variable que afecta en gran medida a las relaciones sexuales es el alcoholismo en Nicaragua, tanto en heterosexuales como homosexuales. Cuando los hombres toman alcohol se produce una descarga emocional que les "permite" estar tristes, llorar o hacer estallar su dolor, así como dar salida a sus deseos eróticos o anhelos de intimidad reprimidos (op. Cit, p. 205). Es curioso como esa vulnerabilidad, a nivel social y entre iguales, no es criticada ni puesta en entredicho su masculinidad, porque según argot "Nica”, "bolo no vale" (bolo significa borracho en nuestro contexto español). En esta línea, hay que subrayar que en Nicaragua hay una alta relación entre consumo de alcohol o "guaro" y la violencia ya que, al tener los sentimientos a flor de piel, con la desinhibición que conlleva, cualquier rechazo de parte de su mujer a su búsqueda de intimidad puede rápidamente transformarse en ira y resentimiento terminando en comportamientos violentos.

\section{Nicaragua: situación del VIH y su respuesta a la epidemia, 2006}

Centroamérica es la subregión más afectada, después del Caribe, por VIH/sida en la región de América Latina y el Caribe. Se analizan los datos de Costa Rica, El Salvador, Guatemala, Honduras, Panamá y Nicaragua. En Centroamérica se encuentran cuatro de los seis países de América Latina con mayores tasas de prevalencia de infección por $\mathrm{VIH}$, siendo en dos de ellos la tasa de prevalencia superior al 1\%. Los grupos más vulnerables son los trabajadores comerciales del sexo -TCS-, los hombres que tienen relaciones sexuales con otros hombres -HSH- y las personas privadas de libertad.

El objetivo fundamental del estudio era establecer una línea base para medir el progreso e identificar nuevos desafíos para el Proyecto Regional de VIH/ sida del Banco Mundial. Consiste en proporcionar conocimiento y herramientas para los responsables de formular las políticas y decisiones en todos los países de la región, para manejar y controlar el VIH/sida y las infecciones oportunistas.

Según el Banco Mundial (2006: 13) "todos los países centroamericanos han establecido respuestas nacionales coordinadas para tratar la epidemia de VIH". No obstante, hay que focalizarse en aquellos aspectos más débiles para hacer un sistema más efectivo. Por ejemplo, en cuanto a la prevención, el reto principal sigue siendo alcanzar eficazmente los grupos más vulnerables con intervenciones basadas en evidencia y costo-efectivas, incluyendo las estrategias de prevención apropiadas para promover prácticas sexuales y conductas reproductivas más sanas y seguras.

En cuanto al tratamiento hay que subrayar que todos los países centroamericanos están proporcionando tratamiento y atención de salud a las Personas que Viven con el Virus del Sida -PVVS-, incluyendo el acceso a las terapias antirretrovirales (op. Cit., pp. 15). En los últimos años en la mayoría de los países los medicamentos genéricos están ahora disponibles mediante procesos de licitación institucional o a través de organismos de adquisiciones y las fundaciones internacionales.

Las conclusiones de este estudio desarrollado por el Banco Mundial en Nicaragua, señalan que los grupos vulnerables son los trabajadores sexuales, hombres que tienen sexo con hombres, los privados de libertad, las mujeres, los jóvenes vulnerables, huérfanos, grupos indígenas y afrodescendientes, grupos migratorios y, por último, discapacitados. A continuación, exponemos los resultados obtenidos en cada uno de estos grupos.

- Trabajadores sexuales. En 2003 hubo un 1,7\% de prevalencia de VIH en este sector. La pobreza 
extrema, la desintegración familiar, el desempleo y la falta de oportunidades educativas son algunos de los factores por lo que estas personas ejercen estas actividades.

- Este grupo pertenece mayoritariamente a las poblaciones de Chinandega y Bluefields, oscilando su prevalencia entre 1 y $4,9 \%$, por encima de Managua que tiene menos del $1 \%$.

- Hombres que tienen sexo con hombres. En el año 2002 la prevalencia estimada para este grupo era aproximadamente de 9,3\%. Un 98\% habían escuchado hablar sobre $\mathrm{VIH} /$ sida, un $86 \%$ reconocía que el uso del condón era una buena práctica para prevenir el VIH/sida y sólo el $41 \%$ de los entrevistados manifestaban el deseo de cambiar su comportamiento sexual para reducir el riesgo de adquirir VIH/sida (op.cit., 7).

- Privados de libertad. En un estudio realizado en el Centro Penitenciario de Tipi Tapa (Departamento de Managua), de 300 entrevistados, más de la mitad manifestaron que no habían usado condón en su última relación sexual. La prevalencia de VIH fue de un $1 \%$.

- Mujeres. Desde 1987 a 2004 se registraron 2,79 casos de VIH/sida en hombres por cada mujer. Sin embargo, la situación de América Central y concretamente de Nicaragua, hacen a las mujeres más vulnerables. Una de las razones es la necesidad de muchas mujeres de movilizarse fuera del país a regiones donde la epidemia del VIH/sida ha tenido un mayor impacto.

- Jóvenes vulnerables. La falta de oportunidades educativas y la carencia de información oportuna aumentan la vulnerabilidad de los jóvenes. Durante el periodo comprendido entre 1987 y 2004 un 2\% de los casos acumulados correspondía a menores de 15 años, mientras que, del total de fallecidos a causa del sida, el 3\% pertenecía a este grupo de edad.

- Huérfanos. En 2005, según UNICEF, habían alrededor de 4.000 niños huérfanos a causa del sida en Nicaragua, lo que corresponde al 3,5\% del total de huérfanos que se notifican en el país.

- Grupos indígenas y afrodescendientes. Según el Plan Estratégico Nacional de VIH/sida 20052009, en la RAAS la prevalencia de VIH/sida era aproximadamente del $47,1 \%$ por cada 100.000 personas en 2004, mientras que en la RAAN era de $25,8 \%$ por cada 100.000 personas el mismo año. Al ser Nicaragua un país multiétnico, encontramos realidades culturales muy diferentes en diversas zonas del país, sobre todo en las regiones del Atlántico.

- Grupos migratorios. Según un estudio desarrollado en 2005 por el Instituto Mexicano de Salud Pública, en el Departamento de Rivas, Nicaragua, la mayoría de los casos de VIH detectados en 2001 correspondían a personas que habían adquirido el virus en otro país. El 99\% de los entrevistados tenían conocimiento del VIH/sida.

- Comparando estos resultados con nuestra investigación, volvemos a cuestionarnos ¿entonces qué falla? No es comprensible que los encuestados conozcan el VIH/sida y en cambio sigan habiendo infectados y se siga transmitiendo el virus.

- Discapacitados. Existen 593.000 personas con discapacidad en Nicaragua según la OPS. Con respecto a este colectivo, no existe información sobre la situación del VIH/sida en Nicaragua.

Entre los resultados principales del estudio, en relación con el resto de países centroamericanos, se encuentra el hecho de que Nicaragua todavía tiene tasas de prevalencia de infección por VIH en los adultos debajo de un $1 \%$, concretamente con un $0,2 \%$, seguido de $\mathrm{El}$ Salvador y Costa Rica con $0,6 \%$, lejos de los datos de Honduras con un $1,6 \%$ y Guatemala un $1 \%$.

\section{SIDA: conocimientos, actitudes y prácticas de riesgo de estudiantes y profesores del CUR-Chontales, 2009}

Nicaragua, país del istmo centroamericano, ha modificado en las últimas décadas su perfil demográfico 
y ha experimentado una transición epidemiológica, donde la epidemia del VIH es un contribuyente de este perfil.

Desde 1987 a 2009, el comportamiento de la epidemia ha evolucionado a una epidemia concentrada, la cual se ha mantenido en esta clasificación similar a lo reportada en el informe para UNGASS correspondiente al período 2006-2007. Al terminar 2009, el acumulado alcanza unas 3.262 personas con VIH, 587 casos de sida y 842 fallecidos.

La principal vía de transmisión continúa sigue siendo la sexual con el $86 \%$. Asimismo, hay que destacar el avance en la feminización de la epidemia (1.8 hombres por cada mujer).

En 2009 se publican los resultados de un estudio realizado por la Universidad Pablo de Olavide (Sevilla, España) y el Centro Regional de Chontales -CURChontales- de la UNAN-Managua, para ahondar en los conocimientos y actitudes tanto de estudiantes como de profesorado en el CUR-Chontales-. El proyecto se denominaba "SIDA: conocimientos, actitudes y prácticas de riesgo en estudiantes y profesores en el CUR-Chontales de la Universidad Nacional Autónoma de Nicaragua-Managua. Propuestas para un modelo de Educación Preventiva”.

Según los resultados obtenidos (Morón Marchena, 2009), un $78 \%$ de los estudiantes encuestados pertenecientes al CUR-Chontales, afirman conocer el significado de las siglas $\mathrm{VIH} /$ sida aunque es casi más significativo que un $20 \%$ afirman no saberlo o se equivocan al definirlo. Con respecto a si convivirían con una persona enferma de sida en llamativo que entorno al $43 \%$ responden no saberlo y los que dicen que no, porque se acabarían contagiando.

Por otra parte, cuando se les pregunta si seguirían manteniendo relaciones sexuales si su pareja tuviera sida, más del $51 \%$ dice que dejaría de mantener relaciones sexuales. Sólo un 28,06\% responden que seguirían manteniendo relaciones sexuales con su pareja "únicamente con preservativo".

Entre sus conclusiones destaca que el conocimiento y percepciones de los estudiantes respecto al $\mathrm{VIH} /$ sida es bastante variado, presentando un número medio de alumnos que conocen la enfermedad, sus principales modos de contagio y aspectos preventivos junto a un número no menos significativo de personas que presenta un nivel de conocimiento bastante disperso donde se entremezclan apreciaciones contrastadas con prejuicios y tópicos (op. Cit, p. 231).

Un $17 \%$ de alumnos reconocen que su nivel de conocimiento sobre el tema es bajo o casi nulo. Por otra parte, el conocimiento del profesorado es mucho más alto, afirmando tener un nivel medio de conocimientos sobre el sida en un 56\%, y alto con un $37 \%$.

Casi un 59\% de alumnos manifiesta no utilizar ningún tipo de método anticonceptivo en sus relaciones sexuales, lo que es especialmente preocupante en un contexto donde es precisamente la franja de edad en la que se incluye la adolescencia uno de los segmentos donde la epidemia sigue creciendo inexorablemente en los últimos años. En el caso de los profesores, el $59,63 \%$ declara no utilizar tampoco ningún método anticonceptivo en sus relaciones sexuales.

Un aspecto importante de este estudio han sido las preconcepciones y los prejuicios, ya que un $42 \%$ de los estudiantes opina que no conviviría con una persona que tuviera sida o dicen no saber si lo harían o no, por miedo al contagio. El profesorado, en cambio, casi un $90 \%$ dice no tener problemas por convivir con una persona con sida en su medio académico o laboral, aunque es significativo que existe cierto rechazo en el ámbito estrictamente privado puesto que el 30,59\% afirman que dejarían de mantener relaciones sexuales con su pareja si ésta estuviera contagiada. 
Otro de los aspectos preocupantes del estudio está relacionado con las vías de transmisión de la enfermedad. El 75\% de estudiantes y el $85,54 \%$ de los profesores saben que la enfermedad se transmite mediante el contagio sexual. Sin embargo, el resto de vías de contagio son bastante desconocidas. Sólo el $14,57 \%$ de los estudiantes y el $8,43 \%$ de los profesores saben que es posible el contagio por la transfusión sanguínea.

La presente investigación en el CUR-Chontales concluye con una propuesta de fortalecer acciones dirigidas hacia la información sobre VIH/sida para estudiantes y profesorado. Es importante educar a la comunidad universitaria para que se puede difundir esa información al resto de la población, y trasladarlas al ámbito familiar y laboral de los futuros profesionales (Morón Marchena, 2009).

\section{Seroprevalencia en Jóvenes Nicaragüenses, 2011}

La Fundación Xochiquetzal (2011) desarrolla un estudio denominado "Seroprevalencia VIH/Sida, prácticas sexuales y uso del condón en jóvenes de 18 a 30 años".

Los objetivos del mismo se centraban en identificar los factores más relevantes que vinculan el riesgo ante el VIH con la capacidad de protección de los jóvenes en diferentes municipios del Pacífico de Nicaragua, estableciendo asociaciones muy interesantes que obligan a reflexionar sobre la diversidad de factores que intervienen en su capacidad de protección y que se deben abordar de acuerdo a su propia realidad.

Los municipios elegidos fueron: Managua, C/ Sandino, Tipitapa, Distrito III, Distrito IV, Pochomil (Departamento de Managua); Chinandega, Corinto, SomotilloyVillaNueva(DepartamentodeChinandega); Masaya, Niquinohomo y Nindiri (Departamento de Masaya); y, por último, Rivas, San Juan del Sur, Potosí y San Jorge (Departamento de Rivas).
Entre los resultados más significativos de este estudio se encuentra que 3 de cada 4 jóvenes (77\%) prefieren el condón para protegerse de los riesgos de transmisión por VIH/sida. Por franja de edad, son los jóvenes de entre 18 a 20 años los que afirman esta preferencia, correspondiéndose con el $84 \%$, tanto para mujeres como para hombres. Resulta llamativo que esta preferencia disminuye a medida que incrementa la edad (65\% de 25 a 30 años).

Si tienen información sobre $\mathrm{VIH} /$ sida y métodos anticonceptivos, es curioso que cuando se les pregunta si usaron el condón en su última relación sexual, uno de cada tres jóvenes (32\%), poniéndose de manifiesto mayor uso en los hombres (37\%) y menor en las mujeres (26\%). En cuanto a las razones sobre el porqué no usaron el condón en su última relación sexual, se identificaron estas siete: mi pareja no quiso (7\%), yo no quise $(15 \%)$, no se habló $(22 \%)$, no sé $(3 \%)$, confianza en su pareja (23\%), no teníamos condón $(11 \%) \mathrm{y}$, por último, no era necesario (22\%).

Por otra parte, a pesar de que más de 3 cuartas partes de los jóvenes declara que el condón es la mejor manera de prevenir el VIH, sólo una tercera parte dispone de ellos en el momento de la encuesta, con una clara predominancia de los muchachos (38\%) con respecto a las muchachas (24\%), en la que sólo una de cada cuatro tiene condones. La mayoría de los jóvenes (41\%) accede a los condones por la vía de la compra en farmacias, supermercados y gasolineras, que constituye el canal de distribución mayoritario para todas las edades y territorios. Sin embargo, la disponibilidad de condones al momento parece asociarse con la oferta que realizan las unidades de salud, en tanto coinciden los segmentos de mayor disponibilidad (mayores de 20 años y Municipios periféricos) con aquellos que acceden a los condones en estas unidades.

Con respecto a la última relación sexual, se evidencia un comportamiento diferencial entre hombres y mujeres. Mientras las muchachas de todas las edades 
han tenido muy mayoritariamente $(87 \%)$ relación con su propia pareja estable, los muchachos manifiestan mayor nivel de diversidad de parejas ya que solo dos de cada tres (66\%) lo hicieron con su pareja estable. La condición de multiplicidad de parejas, coincide con lo descrito en capítulo anterior cuando se hizo referencia al número de parejas estables.

Con respecto al grado de fidelidad de los jóvenes, de las muchachas que declaran haber tenido relaciones sexuales, el 85\% las tuvo "solo" con su pareja estable, un $9 \%$ tuvo relaciones con su pareja estable y con parejas ocasionales y un $6 \%$ sólo tuvo relaciones con parejas ocasionales. En cambio, en el caso de los muchachos reflejan menor grado de fidelidad ya que sólo el 56\% tuvieron relaciones sexuales con exclusividad a su pareja estable, mientras uno de cada tres $(30 \%)$ mantuvieron relaciones tanto con su pareja estable como con ocasionales. El 14\% tuvo relaciones solo con parejas ocasionales.

Hay que destacar, entre las conclusiones de este estudio, que las razones vinculadas a los roles o actitudes de dominación o subordinación propias de las relaciones de poder entre género predominantes, agrupadas en la denominación "desigual control”, están presentes y son la principal razón de no uso de condón en las relaciones con los dos tipos de pareja (44\% y 59\%), pero también evidencia que las relaciones con pareja ocasional favorecen la mayor vulnerabilidad de los jóvenes en tanto su carácter de eventual hace que no puedan incidir en las condiciones en que se da la relación y se parte de un grado variable desconocimiento de la pareja, que terminan por favorecer la desigualdad de género.

Según el estudio de Fundación Xochiquetzal (2011), es obvia la incidencia de la desigualdad de género en las razones basadas en las desigualdades en el control de la relación sexual, que operan tanto en mujeres como en varones dado que se han agrupado los roles de sumisión y dominación, que se incrementan aún más cuando se relacionan con parejas ocasionales con las cuales las probabilidades de diálogo y concertación de las condiciones de la relación sexual se reducen drásticamente.

En cuanto al concepto de "fidelidad", para las mujeres es un criterio que opera tanto para estables como para ocasionales, mientras que para los hombres la brecha por tipo de pareja se amplía significativamente, es decir, confía más en su pareja estable $(30 \%)$ porque asume que no podría serle infiel y se decide no usar condón, pero reduce su confianza en sus parejas ocasionales por lo cual decide usar condón, de ahí que este grupo de razones reduce también su peso como razón de no uso del condón (12\%).

La mayor evidencia que muestra el estudio es la gran complejidad y diversidad de elementos, dinámicas y relaciones que confluyen para configurar la vulnerabilidad o la capacidad de protección de los jóvenes, que resulta en una gran diversidad de situaciones, difícilmente reducibles u homogenizables con base a alguna norma de interpretación o de acción.

La desigualdad de género emerge desde las justificaciones del no uso de condón en la última relación sexual y subyacen en las probabilidades de uso permanente del condón. Los aspectos que lo confirman son: la permanente desigualdad en la vulnerabilidad entre muchachos y muchachas y se expresa de múltiples formas, ya sea en el hecho de no hablar sobre el uso del condón o acerca de las condiciones de las relaciones sexuales, ya sea en la confianza en la promesa de fidelidad que reduce protección en muchachas pero no afecta la protección de los muchachos, o bien por el hecho de estar planificado como razón de no uso de condón, que es precisamente el único anticonceptivo masculino, de modo que la responsabilidad de la anticoncepción se “delega” en las muchachas.

Uno de los aspectos que no exploraron en este estudio han sido las desigualdades de poder en la sexualidad, 
concretamente las que tienen lugar dentro de la familia, la escuela y el trabajo, pero con mucha seguridad no solo pueden tener una prevalencia relevante sino un importante rol en el condicionamiento de la capacidad de protección de los jóvenes.

Otro de los aspectos que resultaron de interés es que el estudio confirma que estar bien informados $\mathrm{y}$, sobre todo, conocer la situación de la epidemia del $\mathrm{VIH} /$ sida en la localidad, resultó ser un factor de alto beneficio para su protección, esto nos indica que es conocimiento situacional y evidencias de vida real lo que más requieren los jóvenes, por el gran volumen de "conocimiento científico" que llena los mensajes y talleres de capacitación.

\section{Conocimientos, actitudes y prácticas de riesgo en VIH de la población trabajadora de la Maquila, 2012}

La Organización Internacional del Trabajo -OITpublica el proyecto denominado "Conocimientos, actitudes y prácticas sobre el VIH y el SIDA en población trabajadora de la Maquila en Nicaragua", un proyecto de prevención y mitigación del impacto del VIH y el sida a partir del mundo del trabajo.

Este proyecto lo pone en marcha el Centro de Investigación en Salud, Trabajo y Ambiente de la Universidad Nacional Autónoma de Nicaragua-León (UNAN-León) junto con la OIT y se identificaron las vulnerabilidades existentes en la población trabajadora de las empresas del sector maquila, sobre sus conocimientos, actitudes y prácticas en relación al VIH y el sida.

Se encuestan a 514 trabajadores del sector maquila, entre 18 y 55 años. El 58\% fueron mujeres y el 42\% hombres, procedentes la mayoría de las mujeres de la ciudad, casadas o en unión libre, con estudios de secundaria.
El 75\% de la población conoce el significado de las siglas VIH, el 13\% desconoce qué es el sida y un 39\% considera que VIH y sida es lo mismo. Según estos datos, los grupos etarios con mayor edad tienen menor conocimiento. En cuanto a las formas de transmisión sexual, el $50 \%$ desconoce que el sexo oral es una forma de transmisión del VIH, un $42 \%$ desconoce que las relaciones sexuales anales son una forma de transmisión sexual, un $1,4 \%$ de los hombres y un $2,7 \%$ de las mujeres desconocen cualquier forma de transmisión.

Con respecto a la prevención, el 40\% afirma ser fiel a su pareja y no considera necesario hacerse la prueba de VIH, mientras que un $47 \%$ opina que la prueba es necesaria aunque haya fidelidad entre la pareja.

Por otra parte, el 92\% de los entrevistados han tenido relaciones sexuales alguna vez en su vida. Un $20 \%$ siempre usa el condón en cualquier tipo de relación sexual, el 46\% utiliza condón con su pareja actual, el $20 \%$ utiliza condón con parejas ocasionales y el 34\% restante nunca ha utilizado condón. Con respecto a dónde los consiguen, el 56\% los compran en las farmacias, el $16 \%$ en el centro de salud u hospital, un $8 \%$ en supermercados y ventas de abarrotes, un $19 \%$ en otros sitios y un $1 \%$ en el lugar de trabajo.

En cuanto a las situaciones de vulnerabilidad, es preocupante que un 69\% de las personas entrevistadas con edades comprendidas entre los 30 y 34 años tienen prácticas de mayor riesgo de infección por el VIH. Un $50 \%$ delas mujeres nuncautiliza condón en las relaciones sexuales anales, un $44 \%$ de los hombres considera que no es necesario utilizar condón durante el sexo oral, un $32 \%$ de quienes tienen relaciones sexuales anales utiliza siempre condón, un 29\% de los trabajadores se realizó la prueba del VIH voluntariamente en el último año y más de la mitad que lo hizo recibió consejería y un $11 \%$ ha tenido relaciones sexuales bajo los efectos del alcohol en alguna ocasión. 
Entre las conclusiones de la OIT (2012) se encuentra capacitar sobre el VIH y el sida y el mundo del trabajo a tomadores de decisiones del Ministerio de Trabajo (MITRAB), con el fin de garantizar el apoyo para incluir este tema en el plan de trabajo de la institución. Además, es importante sensibilizar a las Comisiones Mixtas de salud e higiene, nacionales y locales, para que incluyan en el plan de higiene y seguridad el tema del VIH/sida. Por otra parte, hay que realizar procesos de capacitación dirigidos a empleadores y sindicalistas, con el objetivo de sensibilizarlos sobre el impacto del $\mathrm{VIH} /$ sida.

También resaltan la importancia de realizar campañas de promoción de la prueba voluntaria del VIH dentro de los ambientes de trabajo, con apoyo de las autoridades del sector salud; proporcionar información sobre el uso correcto y consistente del condón como una forma de prevención efectiva.

Por último, es destacable la propuesta de intervención que plantean sobre la realización de programas comunitarios relativos al VIH como parte de las actividades de responsabilidad social empresarial. Esta propuesta coincide con nuestro objeto de realizar una intervención socioeducativa, con líderes juveniles, para trabajar la sensibilización, información y formación desde la comunidad, en la comunidad y para la comunidad.

\section{Desarrollo comunitario y calidad de vida en Juigalpa, 2012}

En 2012 la FAREM-Chontales (UNAN-Managua) desarrolla, junto a la Universidad Pablo de Olavide un estudio sobre VIH/sida, denominado "Desarrollo comunitario y mejora y calidad de vida en Juigalpa (Nicaragua) III Fase UNAN-Managua FAREMChontales, Nicaragua en Drogodependencia, Conductas Sexuales de Riesgo, Prevención de VIH/ SIDA y Salud Laboral”.
Este estudio lo desarrollan ambas instituciones dentro de la Convocatoria de Proyectos de Solidaridad y Cooperación al Desarrollo del Excelentísimo Ayuntamiento de Dos Hermanas (Sevilla, España). $\mathrm{Su}$ objetivo era fortalecer las acciones institucionales en la promoción de salud y prevención de conductas de riesgo en la población vulnerable de la ciudad de Juigalpa. Por tanto, no se trata de un proyecto de investigación sino de intervención.

La población destinataria de este proyecto son niños y niñas menores de 13 años, y adolescentes de los colegios e institutos de la ciudad de Juigalpa, los cuales suman un total de 18.456 estudiantes, así como a los trabajadores de las instituciones del Estado y empresas públicas y privadas debidamente constituidas.

Las actividades que se llevaron a cabo, entre otras, fueron:

- Organización de la comisión para el desarrollo de trabajo comunitario de la Calidad de Vida, Fortalecimiento del Comité de Padres y Madres de Familia COPAMA.

- Emisión de un programa radiofónico, publicadas 10 transmisiones.

- Elaboración de seis materiales educativos (folletos).

- Siete seminarios dirigidos a profesores y padres de familia.

- Doce charlas educativas a estudiantes y líderes juveniles (1084 participantes).

- Dos ferias educativas (10.000 participantes).

- Dos foros para el desarrollo de la calidad de vida.

En cuanto a los resultados esperados, encontramos:

- Encuentros de trabajo de los cuales un encuentro será para reactivar OCAVI-COPAMA y 14 con padres de familias.

- Elaboración y promoción de material educativo que oriente acerca de drogodependencia, conducta de riesgo sexual y $\mathrm{VIH} /$ sida.

- Transmisión de programa radial (10 emisiones).

- Tamizaje de VIH/sida mediante la aplicación de 
Pruebas rápidas.

- Tres ferias educativas sobre temas alusivos a la drogodependencia, conducta de riesgo sexual y VIH/sida.

- Liga del saber sobre temas alusivos a la drogodependencia, conducta de riesgo sexual y VIH/sida.

- Foros educativos acerca de drogodependencia, conducta de riesgo sexual y VIH/sida.

- Concursos de murales inter-colegial sobre la consolidación de lo aprendido en todas las actividades del proyecto.

\section{Conocimientos y prácticas de riesgo en VIH/sida. Una estrategia de Cooperación en Educación para el Desarrollo en Nicaragua, 2013}

Este estudio supone un gran avance en cuanto a datos de $\mathrm{VIH} /$ sida ya que ha existido, en Nicaragua en general y en Chontales en particular, una dificultad notable debido a la escasa existencia de registros oficiales, la escasa actualización de datos donde sí existen registros $y$, por consiguiente, el subregistro que nos confirman los informantes claves del estudio. Todo ello provoca confusión y complejidad debido a la disparidad de cifras según las fuentes consultadas.

Los participantes de la investigación consideran la problemática del VIH-sida como un eslabón no resuelto de índole cultural y social, una lacra social que no evoluciona a medida que evoluciona la sociedad en su conjunto.

De la misma manera, la influencia de una sociedad machista crea desconfianza hacia los valores culturales trasmitidos de generación en generación, propiciando que los jóvenes no terminen de adquirir una base sólida respecto al VIH-sida/ETS. La juventud nicaragüense va avanzando generando un cambio cultural en educación teórica-profesional pero no se acerca a la educación sexual y el respecto a la vida en el sentido más amplio de la palabra.
Llama la atención que un gran porcentaje de los estudiantes encuestados $(58,73 \%)$ afirma no utilizar ningún método anticonceptivo, por el contrario, un 39, 04\% declara sí utilizar alguno de estos métodos. Algo significativo es que un $17,30 \%$ de estos jóvenes, por algún motivo no han sabido o no han querido contestar a esa pregunta (Pérez-Pérez, 2013).

Es significativo el porcentaje de encuestados que afirman no utilizar métodos anticonceptivos, la mayoría de estos encuestados tienen un nivel de estudios medio o medio-alto, por lo que se presupone que conocen los riesgos que puede llevar el mantener relaciones sexuales sin la utilización de estos métodos.

Según Pérez-Pérez, 2013, del 39,04\% de jóvenes que afirman utilizar algún método anticonceptivo, podemos comprobar cómo el 38,91\% dicen utilizar métodos anticonceptivos de barrera (preservativos/ diafragma), seguidos por un 34,18\% que utilizan métodos hormonales (parches, píldoras, DIU, etc.), sólo un 8,36\% afirma utilizar métodos anticonceptivos permanentes (vasectomía, ligadura de trompas...).

Al preguntarles si seguirían manteniendo relaciones sexuales con su pareja, si ésta está afectada con la enfermedad del sida, un 28, 06\% afirman que seguirían manteniendo relaciones sexuales, pero siempre utilizando preservativo para así no contraer la enfermedad. Tan solo un 2,58\% de los estudiantes dicen que seguirían manteniendo relaciones sexuales con su pareja, pero utilizando métodos anticonceptivos orales, lo cual puede evitar un embarazo, pero no puede evitar el contagio de la enfermedad. Sin embargo, un $51,09 \%$ de estos estudiantes dicen que no mantendría relaciones sexuales con sus parejas si ésta estuviese enferma con el sida. Por último, apreciamos que existe un $18,07 \%$ de estudiantes que no saben si seguirán o no manteniendo relaciones sexuales con sus parejas si estas estuvieran afectadas por la enfermedad mencionada anteriormente (Pérez-Pérez, 2013). 
Resulta preocupante la existencia de personas que seguirían manteniendo relaciones sexuales $\sin$ protección si sus parejas estuvieran afectadas por el VIH, ya que es una manera de exponerse a una infección o enfermedad de transmisión sexual, por lo que si existen métodos que pueden evitar el contagio ¿por qué no los utilizan? Esta respuesta no concuerda mucho con otras que han dado en otras preguntas, ya que si realmente tienen un nivel alto sobre la enfermedad resulta incomprensible que responda de esta manera.

Entre sus conclusiones se encuentran dos grandes obstáculos de la sociedad chontaleña ante el VIH/ sida. En primer lugar, la influencia de la iglesia que obstaculiza en términos de salud y educación sexual, según los propios participantes (Pérez-Pérez, 2014). En segundo lugar, la superioridad del hombre sobre la mujer, creando desconfianzas y malinterpretaciones sobre cualquier evolución de conceptos relacionados al VIH/sida, relaciones sexuales y métodos de protección. Entendemos el machismo como recoge el Ministerio de Salud de Nicaragua (MINSA, 2010:8) al referirse a él como un "estilo de vida autoritario, individualista, preocupado de sí mismo, generalmente atribuido a ciertos hombres". Según Pérez-Pérez, Morón-Marchena y Cobos-Sanchiz (2015: 19) este estilo de vida es "un factor importante para la propagación del VIH/sida” y así lo confirma el Plan estratégico nacional de lucha contra las ETS/VIH/sida de Nicaragua que refiere "fuerte influencia que ejerce una práctica sexual influida fundamentalmente por una cultura de tipo patriarcal" (Proyecto Acción Sida de Centro América -PASCA-, 2000: 27).

Por otra parte, según Pérez-Pérez (2014: 299) hay aspectos importantes como "la desinformación o la información mal canalizada o mal entendida, la relación con la homosexualidad y la prostitución, que crean culturalmente mitos y estereotipos que dificultan la aceptación social de las personas con VIH”.
Para ser jóvenes con un nivel medio educativo, y haber afirmado que tienen un nivel medio o alto sobre el sida, no es muy alto el porcentaje de encuestados que saben que se puede ser portador de la enfermedad pero que eso no tiene porqué significar que se tenga el sida. Aquí nos encontramos con una contradicción, ya que, si el nivel de conocimiento fuese el que dicen tener, el porcentaje de estudiantes que conocen que se puede tener el VIH, pero no desarrollar la enfermedad debería ser más alto. Esta incongruencia puede venir porque los jóvenes han querido contestar lo "políticamente correcto" diciendo que tienen un conocimiento alto sobre la enfermedad cuando en las siguientes preguntas demuestran no es tan alto como ellos afirman tener.

En definitiva, como señalan Pérez-Pérez, MorónMarchena y Cobos-Sanchiz (2015: 23) "la concienciación, a pesar de la información que se ofrece, es muy escasa pues los jóvenes reciben información no sólo de la escuela, sino también de múltiples vías como las amistades, internet, escuela y la familia, lo que ocurre es que no toda esa información es verídica" ni fiable. Por tanto, es importante trabajar en la concienciación de la juventud en cuanto a las prácticas de riesgo y los estereotipos que también surgieron en esta investigación, porque sólo cuando una persona es consciente, es capaz de lograr un cambio.

\section{Situación de ITS, VIH y Sida en Nicaragua, Monitoreo y evaluación de avances para contener la epidemia, 2013}

La UNAIDS y PASCA, junto con la participación de diversos organismos nicaragüenses como la Comisión Nicaragüense del Sida (CONISIDA), el Ministerio de Educación y Deportes (MINED), la Procuraduría de los Derechos Humanos, el Ministerio de la Familia, Adolescencia y Niñez (MIFAMILIA), entre otros, publica en 2013 el tercer informe de Monitoreo $y$ Evaluación de Avances para contener la Epidemia (y último hasta el momento). 
Este estudio parte de los indicadores del Plan de Monitoreo y Evaluación Nacional de VIH correspondiente al Plan Estratégico Nacional 20122015 para dar a conocer la situación de la epidemia del VIH y la respuesta de Nicaragua.

Según la PASCA (2013: 3) desde su primer diagnóstico en 1987 en Nicaragua, el incremento que ha habido en el número de personas diagnosticadas es "producto del incremento en acceso a pruebas voluntarias y consejerías". Hasta 2012 se acumulaba un total de 7.875 casos de personas afectadas por el VIH con una tasa de prevalencia de 0.21 por 100 habitantes y una incidencia de 32 por 100.000 habitantes. En el último año (2012) se confirmaron 1.011 nuevas personas afectadas por el VIH, diagnosticándose el 91.2\% de los casos de forma temprana.

En cuanto al sexo, la población más afectada es la de los hombres, con un $57 \%$ de los casos frente al $38 \%$ de las mujeres. Con respecto a la edad, el 20\% (201) corresponde al grupo de entre 30 y 34 años, seguido con un 20\% (200) por el grupo de 25 a 29 años, un $16 \%$ de 20 a 24 años y un $11 \%$ de 35 a 39 años. Es decir, nos encontramos con una población muy joven, entre los 20 y 39 años, si bien el estudio resalta que un " $84,5 \%$ (855) de las personas se concentran en el grupo de 15 a 49 años" (op. Cit., p. 4).

Por departamentos, la mayoría de la población afectada por el VIH se encuentra en: Managua (52,4\%), seguido de Chinandega (11,7\%), Regiones Autónomas (6,82\%, repartido entre RAAN -5,2\%- y 1,62\%), Masaya $(6,23 \%)$ y León $(5,63 \%)$. En cambio, los que menor número de casos identificaron fueron: Madriz, Rivas y Estelí donde sólo detectaron 7 personas confirmadas.

Este estudio confirma que existe transmisión activa de VIH en todo el país, con una incidencia del 32 por 100.000 habitantes a nivel nacional.

La principal vía de transmisión del VIH sigue siendo la sexual, teniendo lugar la mayoría en relaciones heterosexuales (92\%), seguido por Hombres que tienen Sexo con Hombres -HSH- (4\%), bisexuales $(2,2 \%)$, población lésbica $(0,1 \%)$ y transmisión vertical $(1,36 \%)$.

Ante esta situación, el Gobierno de Nicaragua sigue trabajando junto con las organizaciones sociales y agencias de cooperación, para dar respuesta efectiva a la epidemia. Sus líneas estratégicas se centran en: la Prevención, Atención y Tratamiento, Profilaxis con Trimetroprin, Infecciones Oportunistas, la Prevención de la Transmisión Materno Infantil y la Capacidad Diagnóstica.

Según el estudio, Nicaragua ha trabajado hacia el fortalecimiento del marco legislativo, político y normativo, incorporando a representantes de organizaciones a los espacios de toma de decisión, centrándose en las poblaciones de mayor riesgo. De esta manera se ha aumentado el uso del condón. Sin embargo, otros estudios inciden en que, a pesar de informar sobre las ITS y el uso del condón, la población, sobre todo la joven, sigue sin utilizarlo y, lo que es más importante aún, sigue sin concienciarse en los riesgos del contagio.

Por otra parte, también PASCA (2013) insiste en la necesidad de trabajar en la discriminación del estigma y discriminación por razones del ejercicio laboral u opción sexual.

En definitiva, y aunque entre los retos del estudio no se recoge, es necesaria e imprescindible para disminuir los estigmas y discriminación, así como para aumentar el uso del condón, educar a la población y trabajar con la juventud, que es el principal grupo de riesgo y en sus manos está el futuro de las nuevas generaciones. Sólo mediante la educación se podrá lograr un verdadero cambio social. 


\section{Situación epidemiológica del VIH y TAR en Nicaragua, 2014}

En el año 2013 la epidemia sigue teniendo un crecimiento sostenido, registrándose 8.813 personas afectadas por el VIH, de los cuales 6.894 son VIH, 796 casos (enfermedad avanzada) y 1.072 fallecidos. Sólo en el año 2013 se registraron 938 nuevas infecciones por VIH. Sigue afectando a los hombres (65\%) sobre las mujeres (35\%), con una prevalencia en $\mathrm{HSH}$ de $7.5 \%$, trabajadora sexual $3.2 \%$ y embarazadas $0.15 \%$ y una prevalencia con respecto a la edad de $0.15 \%$ entre los 20 y 24 años, seguido por un $0.11 \%$ de entre 15 y 24 años y un $0.06 \%$ entre 15 y 19 años.

Al finalizar el año de estudio la tasa de prevalencia nacional era de 236\%, siguiendo los departamentos más afectados (por encima de la media) Chinandega, RAAN y Managua, mientras que los departamentos menos afectados eran: Río San Juan, Nueva Segovia, Matagalpa y las Minas (UNAIDS, 2014).

Con la incorporación de la terapia antirretroviral altamente efectiva (TARGA) ha habido una mayor sobrevida, con mejora de la calidad de vida lo que supone una disminución de la mortalidad para los próximos años.

La principal vía de transmisión del virus sigue siendo la sexual con un $98 \%$, con un $92 \%$ en población heterosexual, $3 \% \mathrm{HSH}, 2 \%$ bisexual, $2 \%$ transmisión vertical y $1 \%$ población trans.

Con respecto a los conocimientos que tiene la población joven nicaragüense, el " $72 \%$ de jóvenes de entre 15 y 24 años identifican correctamente las formas de prevenir la transmisión sexual del VIH y disminuyen los conocimientos erróneos sobre su transmisión, este indicador mejoró en 32 puntos porcentual con relación al 2010 que fue del 47\%" (op. Cit., p. 9). En cuanto a la percepción de riesgo, el 50\% de los adolescentes $\mathrm{y}$ jóvenes considera que todas las personas tienen riesgo de infectarse con el VIH, mientras que un 49\% considera que las trabajadoras sexuales tienen mayor riesgo de contagio.

Si un $94.6 \%$ de los jóvenes afirman que tienen fácil o muy fácil acceso al condón, sólo un $42 \%$ reconocen que el principal beneficio de este método es la prevención de las ITS y del VIH. Asimismo, existe cierta contradicción o, al menos, confusión, ya que un $89.3 \%$ reconocen que el uso consistente y correcto del condón es una forma adecuada de prevenir la infección mientras que un $76.4 \%$ afirman que el VIH se puede prevenir siendo fiel a una sola pareja sexual que no esté infectada.

Por último, sigue sin aparecer dentro de las estratégicas de prevención la educación o formación en educación para la salud y en prevención del VIH/sida, limitándose a la oferta de pruebas de VIH y las consejerías, aparte de fortalecer el acceso al TARV.

\section{MODELOS DE SEXUALIDAD NICARAGÜENSE}

Con objeto de poder entender la cultura nicaragüense con respecto a las prácticas sexuales, es importante conocer los modelos de sexualidad. Esto nos ayuda a comprender por qué se siguen reproduciendo las prácticas sexuales de riesgo, que es la principal forma de contagio del VIH, además que tiene lugar en población mayormente heterosexual y joven, por lo que identificamos se siguen repitiendo los patrones y está muy relacionado con la cultura y la educación del país.

En Nicaragua, según la zona que estudiemos o en la que nos centremos, podemos hablar de diferentes modelos de sexualidad, ya que depende de la historia de los contextos y su cultura tradicional. Nosotros explicaremos en qué consiste el modelo genérico, que es el tradicional, y después abordaremos el modelo mestizo y el reproductivo, que tiene gran influencia en las prácticas sexuales, culturales y educativas de la población nicaragüense. 


\section{Modelo genérico}

Según Montenegro (2000) el modelo genérico son construcciones histórico-culturales de un "deber ser", o lo que muchas veces decimos como "lo normal", para hombres y mujeres, y que incluye formas de relacionarse, una conducta, valores y expectativas permitidas.

Se estructuran y reestructuran adoptando nuevos elementos o cambiando sus formas, a través de la relación dialéctica entre el deber ser y el ser concreto, es decir, entre el ideal y la realidad. Estos modelos genéricos sirven como un elemento de identidad hacia lo interno y de diferenciación hacia lo externo, entre unas sociedades y otras.

Una peculiaridad de los modelos genéricos es que no son totales, sino que a veces se dan sólo en algunos sectores o grupos de la población. Lo que puede cambiar, sobre todo con el desarrollo tecnológico, es la manera o intensidad en que las mujeres viven la subordinación: disminución en los niveles de opresión, ampliación de los espacios de participación y posibilidades de desarrollo, entre otros.

En el caso de Nicaragua, el sistema dominante ha readecuado los modelos genéricos en correspondencia a los momentos de cambio estructural. Por ejemplo, Nicaragua tardó más que otros países en incorporar a las mujeres a la igualdad de derechos que postuló la Modernidad, y con la crisis de la Revolución (1979) se generaron los principales cambios en el actual modelo de dominación (Montenegro, 2000).

Nicaragua se caracteriza por su multietnicidad por lo que las contradicciones y transformaciones en los modelos de género son bastante complejas. Durante años han coexistido en el país dos formaciones sociales diferentes: la del Atlántico, surgida de la colonización directa de los ingleses, que dio origen a las diversas etnias que la habitan (zonas que comprende a la Región
Autónoma Atlántico Norte y la Región Autónoma Atlántico Sur); y la del Pacífico, con patrones de vida occidentales y latinos, derivados de la dominación española (modelo mestizo y que responde al resto de departamentos y comarcas).

\section{Modelo mestizo}

Este modelo mestizo se origina con la conquista de España en tierras nicaragüenses lo que supuso aparte de la ocupación de la tierra, el nacimiento de una nueva etnia mediante la violación de las mujeres indígenas, la derogación de las lenguas autóctonas y la imposición de otra lengua, otra religión y un nuevo orden social. Representa las normas y valores que integraron la cultura campesina del Pacífico y el centro de Nicaragua, articulando las formas patriarcales de la cultura indígena y las formas coloniales (Montenegro, 2000).

En esta época de conquista coexistieron tres morales tradicionales: la hispana fundada en la honra, la india centrada en el carácter sacrosanto de la familia $\mathrm{y}$, por último, la mestiza que era la viva imagen de la ilegitimidad: violación, rapto o burla que para los indios fue motivo de deshonra y precio humillante de su derrota. Para éstos últimos, ser "hijo de la chingada" era la marca de su ilegitimidad y bastardía.

Cuando una mujer indígena tenía un hijo consecuencia de violación, rapto o concubinato con el colonizador, solía buscar el apoyo de su comunidad (que tendía a rechazarla) e identificaba a su hijo como indio, o buscaba reconocimiento del padre blanco para que pudiese vivir en libertad por ser mestizo y estar al margen del orden jurídico colonial. En este último caso, el hijo se desidentificaba con la cultura de la madre pasando a identificarse con la del padre. Esto provocaba el machismo que existe hoy día en Nicaragua: violenta humillación de la mujer y violenta afirmación del padre (Montenegro, 2000).

1 Este término aparece en el libro "El Laberinto de la Soledad" publicado en 1950 por Octavio Paz, Premio Nobel de Literatura. 
Este comportamiento machista con el tiempo reproduce el poder arbitrario del conquistador y su indiferencia ante la prole engendrada, así como el desprecio hacia la mujer y el resentimiento con la madre.

Una de las herencias de la colonización española en Nicaragua han sido los valores culturales arraigados, en mayor medida, por la Iglesia y el catolicismo. Estos valores son: la voluntad y el amor, y el honor.

- La voluntad y el amor: la doctrina católica establecía el consentimiento individual y su derecho a ejercer la libre voluntad al casarse. Esa libertad se traducía en el amor. El amor era la expresión de la voluntad para casarse, aunque muchas veces "el término mujer enamorada significaba una mujer que se embarcaba públicamente en actividades sexuales repetidas, no una mujer enamorada" (Seed, 1991).

- El honor: supone un código social basado en el respeto, es decir, la estima que una persona tenía sobre sí misma, así como la estima en que la sociedad la tenía. Cada persona tenía que "defender su reputación”. Este honor tiene también una diferencia en cuanto al género. La defensa del honor para los hombres implicaba una voluntad de lucha, de usar la fuerza para defender la reputación propia en contra de quienes la impugnaran; por tanto, la cobardía suponía una pérdida precipitada del honor. En el caso de las mujeres, la defensa del honor se relacionaba con la conducta sexual (permanencia de la castidad antes del matrimonio y después la fidelidad); las relaciones sexuales antes o fuera del matrimonio, en caso de conocerse, demolerían el honor de una mujer y su reputación (Montenegro, 2000).

La característica más importante del honor era la preservación de la intimidad, las apariencias; es decir, más que la moral privada se trata de la falta de revelación al público "si lo haces, que no se enteren". En 1776 se promulga en España el requerimiento de consentimiento de los padres para la selección de un cónyuge de todas las personas menores de 25 años (Seed, 1991). Esta práctica se extiende a las Américas en 1778 y pasó de un honor como virtud a un honor como estatus (diferencia de riquezas, ingreso o estatus social).

\section{Modelo reproductivo}

Aunque se ha ido avanzando en el modelo genérico heredado, es cierto que aún prevalece el modelo cultural que subordina la mujer al hombre, y la creencia de que el trabajo doméstico y el cuidado de los niños son tareas exclusivas de las mujeres. Siguen existiendo situaciones de gran desigualdad entre hombre y mujer como, por ejemplo: paternidad irresponsable, violencia doméstica y restricción del tiempo de las mujeres, aunque es cierto que las nuevas generaciones empiezan a reflexionar sobre su situación y reivindicar un cambio, aunque no es tan latente "de puertas hacia fuera”.

Este modelo genérico imperante y las consecuencias de la discriminación sexual ha provocado escaso control en la capacidad reproductiva de las mujeres, por lo que podemos observar en Nicaragua: altas tasas de fecundidad, elevado número de embarazos juveniles, elevada tasa de crecimiento demográfico, etc.

El hombre se considera "el jefe de la casa" y tiene el rol de protector de la familia, proveedor del hogar y sujeto a privilegios, mientras que la mujer está "subordinada" al marido. Asimismo, los altos niveles de consumo de "guaro" (ron, alcohol) y esa cultura machista heredada genera múltiples casos de violencia de género o machista (Montenegro, 2000).

En 1961 nace el Frente Sandinista de Liberación Nacional (FSLN), bajo la dirección de Carlos Fonseca, seguidor de los principios ideológicos y del movimiento iniciado por el guerrillero nicaragüense Augusto César Sandino. Es en 1984 cuando es elegido presidente Daniel Ortega Saavedra al frente del FSLN, aunque 
finaliza su gobierno en 1990 y vuelve a ser reelegido en 2006.

Con este cambio de gobierno y de valores culturales se avanza en el progreso y el desarrollo humano de la población nicaragüense. El lema del gobierno actual es "Nicaragua cristiana, socialista, solidaria", lo que, en nuestro contexto, podría parecer contrapuesto (por cultura tradicional) "socialista y cristiano", si bien ambas ideologías no tienen por qué ser contrapuestas. Sin embargo, este pensamiento ha quedado anclado en el pasado y las sociedades poco a poco van avanzando en pluralidad de pensamientos, creencias y valores, aunque siempre ajustado a su línea ideológica tradicional (liberal-conservador).

El FSLN promulga un sistema democrático y participativo con el pueblo, aunque algunas voces resaltan la falta de tolerancia ante opciones y liderazgos nuevos que se alejan del control de la línea oficial del partido, controlada por el secretario general, Daniel Ortega y una burocracia que parece estar más comprometida con personas que con principios o programas (Torres, 2003).

Los valores que promulga el FSLN son, como partido unitario, el principio de la equidad entre mujeres y hombres, así como los relevos generacionales, participación de las mujeres en los organismos de dirección del partido, en los puestos de elección popular, y en cargos de responsabilidad gubernamental y no gubernamental (Torres, 2003), "aspirando a que esta participación sea equivalente al peso que las mujeres tienen en la vida familiar, social y económica de la nación”.

Tras una revisión bibliográfica en MiFamilia, no hemos encontrado objetivos concretos sobre la emancipación del rol de la mujer en los hogares nicaragüenses, ni erradicación de la superioridad del hombre sobre la mujer, aspectos que ayudarían mucho a fomentar la igualdad entre mujeres y hombres y, con ello, mejoraríamos las prácticas sexuales y reproductivas de la población (Torres, 2003).

MiFamilia plantea, entre sus líneas estratégicas, algunos aspectos que podríamos resaltar, aunque de manera transversal quizás para mejorar estas condiciones de subordinación:

- Promoción de derechos en la familia; acciones que fomentan y estimulan la práctica de estilos de vida saludables, motivan la participación comunitaria a fin de procurar, conservar y mejorar las condiciones de vida deseables para la población.

- Desarrollar una conciencia de pertenencia, a través de campañas públicas de divulgación y sensibilización sobre derechos y valores para la defensa de ideales y prácticas que nos permita alcanzar justicia para todos.

Por otra parte, y relacionado con el ámbito que abordamos anteriormente de participación ciudadana, MiFamilia, plantea:

- Fortalecimiento de la democracia directa, a través de la integración de personas, líderes comunitarios, consejos del poder ciudadano, que participan y promueven el desarrollo de actividades de interés social comunitario, basado en el principio de solidaridad y en valores de confianza y reciprocidad.

Sin embargo, quisimos seguir profundizando en las estrategias que lleva a cabo este ministerio, encargado precisamente del bienestar de las familias, y que puedan afectar o beneficiar a nuestro objeto de estudio: sexualidad y reproducción, VIH/sida, etc. El ministerio se rige a través de unas líneas generales de acción que concretan las líneas estratégicas, entre las que destacamos:

- Contribuir a la prevención y atención de los factores de riesgo y todas las formas de violencia en la familia y contra niños/as, adolescentes, adultos mayores y a personas con capacidades diferentes.

- Promover con las instituciones del Estado y la sociedad en general, la formación de 
comportamientos responsables en el desarrollo integral, solidario y con equidad de género.

Estas circunstancias de desigualdad de género, valores tradicionales, modelos de reproducción sexual, etc., están muy relacionados con el VIH/sida. Nimehuatzin (1995) realiza una investigación cualitativa sobre comportamiento de alto riesgo ante el sida en Nicaragua centrada en cuatro ciudades: Bluefields, Puerto Cabezas, Corinto y Managua, que suponen un potencial para incrementar rápidamente el VIH/sida:

- Altos índices de enfermedades transmisibles sexualmente (ETS) en las principales áreas urbanas y puertos.

- Crisis económica que incrementa el sexo transaccional.

- Alto número de hombres que tienen sexo con hombres.

- Falta de distribución sistemática de condones.

- Falta de aceptación cultural y mínimo uso del condón.

- Desinformación generalizada y miedo al VIH/sida.

- Penalización de la sodomía (Artículo 204 de la Ley de Reformas al Código Penal) que es un obstáculo legal para las actividades de prevención. La sodomía hace referencia a determinados comportamientos sexuales: sexo anal (para heterosexuales y homosexuales) y las demás prácticas homosexuales masculinas.

- El mayor índice de transmisión del VIH se produce por la vía sexual (93\%) de los casos y más en concreto en las relaciones heterosexuales (52\% del total de casos).

Ante este panorama, es necesario trabajar en las conciencias de la población, en nuevos discursos de la sexualidad, en la educación para la salud, el papel de las instituciones, transformación de la cultura sexual, desigualdades de género, democratización de la sociedad, la preservación de la vida y el desarrollo humano, entre otros. Todo ello debe ir acompañado de campañas de sensibilización y divulgación sobre prevención del VIH/sida y formación para trabajar en la conciencia, para que la población en general, y los jóvenes en particular, logren interiorizar los conocimientos porque sólo así habrá un cambio de conciencia y se logrará una transformación social.

\section{CONCLUSIONES}

En Nicaragua aumenta, aunque de manera controlada la epidemia del VIH/sida, confirmándose que la población a la que está afectando más es a la juventud, dándose casos esporádicos en mayores de 36 años y empezando a aflorar en niños menores de 16 años.

Es importante destacar que los casos mayoritarios son hombres, muy por encima de las mujeres, y tienen lugar en población heterosexual, desmitificando el mito de que "era una enfermedad de drogadictos y homosexuales".

Las relaciones sexuales se inician cada vez más tempranamente, con ciertas diferencias de género. Las chicas suelen comenzar sus primeras experiencias antes que los chicos, con hombres algo mayores que ellas. Relacionado con el machismo, muchas de estas chicas acabarán con un matrimonio precoz para huir del núcleo familiar machista, aunque en la mayoría de los casos el esposo volverá a ejercer la superioridad machista que cree poseer. Los chicos son más libres al iniciar sus primeras relaciones sexuales ya que no se les juzga negativamente por eso, todo lo contrario, cuantas más relaciones consiga tener, más estima personal tiene y mayor reconocimiento social como "hombre". En el caso de la frecuencia de las relaciones sexuales o la durabilidad de las parejas suelen ser parejas un poco más estables al estilo "novio" por parte de las chicas, y por parte de los chicos algo más esporádicas con aquellas chicas que no deciden o no pueden tener parejas estables.

Los embarazos no deseados se producen por varias razones ligadas al desconocimiento o a los tabús que 
existen sobre los métodos anticonceptivos, a las ideas erróneas sobre los ciclos naturales de la mujer y a la impunidad con la que los chicos manipulan a las chicas que desconocen el tema.

El preservativo masculino es el método más usado por la juventud, desconocen (en su mayoría) la existencia del preservativo femenino y utilizan la píldora del día después como método habitual de prevención de embarazo, no como método de emergencia.

Los tabúes, la religión y el machismo están muy arraigados en la cultura nicaragüense, por lo que la prevención del VIH/sida pasa por una educación para la salud, consciente, continua y constante, donde la universidad tiene un gran reto como institución docente e investigadora de la sociedad.

Para conocer la percepción que tienen los estudiantes de la FAREM sobre el VIH/SIDA y, en general, sobre la sexualidad, primero debemos de conocer la cultura sexual nicaragüense. Como señalamos en capítulos anteriores (Montenegro, 2000) podemos resaltar:

La sexualidad y su vínculo con la violencia: los factores que explican el ejercicio de la violencia están relacionados con el control del cuerpo femenino y con valores relativos a la virginidad, fidelidad, placer y autonomía de las mujeres. La violencia sexual para las mujeres representa, aparte de violación y maltrato físico, inhibición y censura del placer femenino.

La relación entre sexualidad y reproducción: ambos aspectos están vinculados al equilibrio psicocorporal de las personas, al relacionamiento humano en distintos planos, a las políticas de población y a la capacidad de las familias para el propio sustento y reproducción en lo material, físico y afectivo.

El ejercicio interventor de los adultos sobre la sexualidad infantil: relacionado con la socialización de la niñez y los roles de género, la preinscripción de normas para niños y niñas, el incesto, los embarazos en adolescentes y el abuso sexual, violación y maltrato a menores.

El imaginario sexual de la población: está configurado con las ideas, creencias y valores que sustentan las prácticas sexuales de la gente, así como con las percepciones y deseos más auténticos sobre la vivencia o construcción de una nueva sexualidad para hombres, mujeres y adultos mayores.

Se considera que en el ámbito de la sexualidad existen restricciones que pasan por la carga de valores y normas que la cultura nicaragüense tiene sobre la sexualidad, dando origen a un tipo de cultura sexual propia.

Por todo ello, resaltamos que tanto la desinformación y la información mal canalizada o mal entendida, la relación con la homosexualidad y los trabajos sexuales crean culturalmente mitos y estereotipos que dificultan la aceptación social de la persona con VIH. Realmente la comunidad tiene prejuicios sobre las formas de contagio de la enfermedad, motivo principal por el que se apartan, desplazan y reniegan de personas con el virus.

De cara a diseñar propuestas de mejora para la prevención e intervención del VIH/sida y prácticas sexuales saludables, la formación de grupos líderes como mentores, la educación para la salud desde edad hasta universitaria, la familia como agente sociabilizador principal, los medios de comunicación, una Ley Prosida y la Igualdad de género real serían propuestas para la mejora de la consideración de personas con VIH y para la prevención de nuevos casos y prácticas sexuales saludables.

Una de nuestras propuestas más fehacientes es crear una red de líderes juveniles y/o comunitarios. Esta idea va en la línea de una de las propuestas que planteó ONUSIDA (2011), en su Informe del Día Mundial del SIDA de 2011, donde señala que hay que invertir en 
líderes juveniles. De esta manera, pidió a todos los países que respaldaran y promovieran la participación activa y el liderazgo de los jóvenes en las respuestas globales, regionales y nacionales.

En definitiva, se trata de implicar a diferentes sectores de la sociedad: maestros, familias, profesionales de la salud, estudiantes, jóvenes, iglesias (especialmente la cristina y evangélica, que son mayoritarias en la región), procuraduría de los $\mathrm{DDHH}$, centros juveniles, asociaciones, turismo, medios de comunicación, etc., para lograr una intervención integral y eficiente.

\section{REFERENCIAS BIBLIOGRÁFICAS}

Banco Mundial (2006). Reduciendo la vulnerabilidad al VIH/SIDA en Centroamérica. Nicaragua: Situación del VIH/SIDA y respuesta a la epidemia. Washington: Banco Internacional de Reconstrucción y Fomento del Banco Mundial.

Branden, N. (1985). Honoring the Self: The Psychology of Confidence and Respect. New York: Bantam Books.

Fundación Xochiquetzal (2011). Seroprevalencia VIH/SIDA, prácticas sexuales y uso del condón en jóvenes de 18 a 30 años. Managua: Fundación Xochiquetzal.

Montenegro, S. (2000). La cultura sexual en Nicaragua. Nicaragua: Centro de Investigaciones de la Comunicación, CINCO.

Morón Marchena, J.A. (2012). Desarrollo comunitario y mejora y calidad de vida en Juigalpa (Nicaragua) III Fase UNAN-Managua FAREM-Chontales, Nicaragua en Drogodependencia, Conductas Sexuales de Riesgo, Prevención de VIH/SIDA y Salud Laboral (no publicada). Managua: UNANFAREM-Chontales y Ayuntamiento de Dos Hermanas.

Morón Marchena, J. A. (2009). SIDA: Conocimientos, Actitudes y Prácticas de Riesgo en estudiantes y profesores en el CUR-Chontales de la Universidad Nacional Autónoma de Nicaragua-Managua.
Propuestas para un Modelo de Educación Preventiva. Informe de Resultados de Investigación. Sevilla: Universidad Pablo de Olavide y UNANManagua.

Nimehuatzin (1995). Investigación Cualitativa sobre comportamiento de alto riesgo frente al SIDA. Family Health International.

OIT (2012). Conocimientos, actitudes y prácticas sobre el VIH/SIDA en la población trabajadora de la Maquila en Nicaragua. Proyecto Prevención y mitigación del impacto del VIH y el Sida a partir del mundo del trabajo. Costa Rica: Oficina Internacional del Trabajo.

ONUSIDA (2011). Acceso universal a prevención, tratamiento, atención y apoyo relacionados al VIH. Nicaragua 2010. Managua: ONUSIDA.

PASCA -Proyecto Acción SIDA de Centro América(2013). Situación de ITS, VIH y Sida en Nicaragua, Monitoreo y evaluación de avances para contener la epidemia año 2012. Disponible en: http:// www.pasca.org/userfiles/NI\%20Informe $\% 20$ de $\% 20$ Indicadores $\% 20$ Priorizados $\% 202012 \% 20$ 31sep2013.pdf.

PASCA -Proyecto Acción SIDA de Centro América(2000). Plan Estratégico Nacional de Lucha contra las ETS/VIH/SIDA en Nicaragua. Nicaragua: PASCA.

Pérez-Pérez, I. (2013). Conocimientos y prácticas de riesgo en VIH/sida. Una estrategia de Cooperación en Educación para el Desarrollo. Tesis Doctoral (no publicada). Sevilla: Universidad Pablo de Olavide.

Pérez-Pérez, I. (2014). “Conocimientos y prácticas de riesgo en VIH/SIDA. Una estrategia de cooperación en Educación para el Desarrollo en Nicaragua". Pedagogía Social. Revista Interuniversitaria, 24, pp. 297-299. Accesible en http://www.upo. es/revistas/index.php/pedagogia_social/article/ view/836. ISSN: 1139-1723. DOI: 10.7179/PSRI.

Pérez-Pérez, I; Morón-Marchena, J. A; CobosSanchiz, D. (2015). Comportamientos y prejuicios de los jóvenes con relación al VIH/Sida: un 
estudio cualitativo con jóvenes universitarios nicaragüenses, en Población y salud en Mesoamérica, vol. 13, $\mathrm{n}^{\circ}$ 1, artículo 4, pp. 1-27. Disponible en: http://www.revistas.ucr.ac.cr/index. php/psm/article/view/19292. ISSN: 1659-0201. DOI: http://dx.doi.org/10.15517/psm.v13i1.19292.

Seed, P. (1991). Amar, honrar y obedecer en el México colonial. Conflictos en torno a la elección matrimonial, 1574-1821. México, Conacultura: Alianza Editorial.

Torres, $\mathrm{M}^{\mathrm{a}}$. J. (2003). Informe sobre
Nicaragua. Disponible en: http:// www.iidh.ed.cr/BibliotecaWeb/Varios/ Documentos/BD_1013860968/PRODECA/ Democratizacion\%20-\%20Inf-Nicaragua.pdf. UNAIDS (2014). Situación epidemiológica del VIH y TARV Nicaragua, año 2013. Disponible en: $\quad$ http://www.unaids.org/sites/default/ files/en/dataanalysis/knowyourresponse/ countryprogressreports/2014countries/NIC_ narrative_report_2014.pdf. 